\title{
Performance of coumarin-derived dendrimer-based fluorescence-linked immunosorbent assay (FLISA) to detect malaria antigen
}

Seon-Ju Yeo ${ }^{1}$, Dinh Thi Huong ${ }^{1}$, Jin-Hee Han², Jung-Yeon Kim³ ${ }^{3}$, Won-Ja Lee ${ }^{3}$, Ho-Joon Shin ${ }^{4}$, Eun-Taek Han ${ }^{2 *}$ and Hyun Park ${ }^{1 *}$

\begin{abstract}
Background: Due to limitation of conventional malaria diagnostics, including microscopy, polymerase chain reaction (PCR), and enzyme-linked immunosorbent assay (ELISA), alternative accurate diagnostics have been demanded for improvement of sensitivity and specificity.

Methods: Serially diluted Plasmodium LDH antigens, Plasmodium falciparum-infected human red blood cells (RBC) derived from in vitro culture or patient's samples were used for evaluation of the performance of fluorescence-linked immunosorbent assay (FLISA). Microscopic examination was used to determine parasite density and the performance of FLISA was compared to ELISA. Finally, sensitivity and specificity of FLISA was determined by human specimens infected with $P$. falciparum, Plasmodium vivax, Toxoplasma gondii, and amoebae.

Results: As a result of FLISA, the fluorescent intensity was highly correlated with antigen amount and FLISA was more sensitive than ELISA. FLISA detected at least $0.01 \mathrm{ng} / \mathrm{ml}$ of pLDH antigen, which showed 1,000-fold higher sensitivity than ELISA. In vitro-cultured P. falciparum was detected up to 20 parasite number/ $\mu \mathrm{L}$ in FLISA but 5120 parasite number/ $\mu$ Lin sandwich ELISA. In vitro P. falciparum-infected RBC number was highly correlated with fluorescent intensity $\left(R^{2}=0.979\right)$, showing that FLISA was reliable for detection of $P$. falciparum and available for quantification of parasite numbers. Furthermore, eighteen patient samples infected with $P$. falciparum $(n=9)$ and $P$. vivax $(n=9)$ showed $100 \%$ of sensitivity (18/18). FLISA showed $96.3 \%$ of specificity (26/27) because one sample of patient blood infected with $T$. gondii gave a false positive reactivity among healthy donors $(n=9), T$. gondii-infected patients $(n=9)$, and amoeba-infected patients $(\mathrm{n}=9)$.
\end{abstract}

Conclusion: FLISA has a keen and high performance to detect malaria antigen, suggesting a potential assay as malaria immunodiagnostic.

Keywords: Coumarin-derived dendrimer, Fluorescence-linked immunosorbent assay (FLISA), Lactate dehydrogenase (LDH), ELISA, Plasmodium falciparum, Plasmodium vivax

\footnotetext{
* Correspondence: ethan@kangwon.ac.kr; hyunpk@wonkwang.ac.kr

${ }^{2}$ Department of Medical Environmental Biology and Tropical Medicine,

School of Medicine, Kangwon National University, Chuncheon, Gangwon-do,

Republic of Korea

'Zoonosis Research Center, Department of Infection Biology, School of

Medicine, Wonkwang University, Iksan, Jeonbuk 570-749, Republic of Korea

Full list of author information is available at the end of the article
}

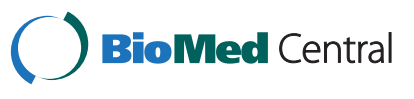

(c) 2014 Yeo et al.; licensee BioMed Central Ltd. This is an Open Access article distributed under the terms of the Creative Commons Attribution License (http://creativecommons.org/licenses/by/4.0), which permits unrestricted use, distribution, and reproduction in any medium, provided the original work is properly credited. The Creative Commons Public Domain Dedication waiver (http://creativecommons.org/publicdomain/zero/1.0/) applies to the data made available in this article, unless otherwise stated. 


\section{Background}

Five human infectious malarias, including Plasmodium falciparum, Plasmodium vivax, Plasmodium ovale, Plasmodium malariae, and Plasmodium knowlesi, remain a serious health issue and are widespread in developing countries, continuing to cause about 219 million cases and one million deaths annually [1]. National malaria mortality rates are, however, particularly difficult to assess reliably and are underestimated in some important endemic areas due to misunderstanding malaria infection [2-4]. Therefore, the establishment of accurate diagnostics of malaria based on quantification of malaria parasite number with high sensitivity and specificity is the top priority for the management of malaria.

As a gold standard of malaria diagnostics, thick and thin blood smears are reliable but it was claimed that in the case of low parasitaemia, aggregation in a specific area of the smear was noticed and blood smearing was less sensitive than immunodiagnostics and PCR methods [5,6]. As an alternative quantitative diagnosis of malaria, over the last few decades, numerous polymerase chain reactions (PCR)-based diagnostic tests targeting RNA or DNA have been developed to confirm the malaria infection in addition to microscopic observation [7-9]. Quantification of malaria infectious parasite numbers in patients with only RNA or DNA copy numbers has been implemented but the requirement of equipped laboratory facilities presents an obstacle to application to a field setting [10]. Due to the limitation of PCR, different immunological assays that use antibodies to detect parasites have been developed with greater potential for adaption to field application than previous approaches, even though immune assays provide sensitivity issues [11]. Therefore, immunological assays have become the basis of most commercial diagnostic test kits, with most interest focused on the use of monoclonal antibodies (mAbs). Using mAbs, enzyme-linked immunosorbent assay (ELISA) method and fluorescence-linked immunosorbent assay (FLISA) have established significant diagnostic biomarkers [12,13]. Resulting devices for the diagnosis of malaria based on malariaspecific antigens, such as histidine-rich protein 2 (HRP2) and lactate dehydrogenase (LDH), have been developed as alternative diagnostics to microscopy and PCR [14].

Microscopy has often been the routine diagnostic technology available in developing countries. However, it has been considered to show variable sensitivity depending on expertise of microscopist [15]. Despite continuous application as key diagnostic tests, microscopy techniques have limitations as universal or targeted donor screening tests due to lack of sensitivity at low parasitaemia [16]. As a higher throughput method of malaria diagnosis, ELISA is suitable for epidemiological surveys [12].

Previously, performance of two monoclonal antibodies (D2H and D7E) targeting conserved 31 amino acids of Plasmodium LDH was shown to be potential to be useful for malaria diagnostics [17]. Besides, light-emitting diode (LED)-based novel organic fluorophore, coumarin-derived dendrimer was developed for malaria diagnostics [13]. As a light source of biosensor, LED has the advantage, because laser diode has various limitations such as expense, difficult operation, limited emission wavelength selections, and a short lifetime [13]. Therefore, development of LED light based diagnostics has advantage as further diagnostics. In this study, the enhanced coumarin-derived dendrimerbased malarial FLISA assay with novel monoclonal antibodies (D2H and D7E) was compared with ELISA.

\section{Methods}

\section{In vitro culture and determination of parasitaemia}

Plasmodium falciparum FCR-3 (ATCC 50005) were purchased from ATCC (Manassas, VA, USA) and strains used in this study were kept in $-80^{\circ} \mathrm{C}$ as frozen stocks. Plasmodium falciparum was cultured by standard procedure as described previously [18], using a 5\% haematocrit of type O-positive human red erythrocytes suspended in RPMI 1640 medium with $5 \% \mathrm{NaHCO}_{3}, 0.5 \%$ Albumax, $25 \mu \mathrm{g} / \mathrm{mL}$ gentamicin and supplemented with heatinactivated $10 \%$ type O-positive human serum. The sixwell plates were placed in an incubator $\left(5 \% \mathrm{CO}_{2}, 5 \% \mathrm{O}_{2}\right.$, and $90 \% \mathrm{~N}_{2}$ atmosphere) at $37^{\circ} \mathrm{C}$, and the medium was changed daily at least $5 \%$ parasitaemia. Blood smears were stained with Giemsa for counting parasite numbers with microscopy under 1,000 $\times$ magnifications. Parasite density was determined as a percentage of infected erythrocytes in fields of total 500 erythrocytes in the study. Animal experiments were performed at the experimental protocol, which was approved by the Animal Care and Use Committee at Wonkwang University.

\section{Purification of coumarin-derived dendrimer-or horseradish peroxidase (HRP)-bioconjugates}

Subcloned cells (D7E or D2H) secreting pLDH were kindly provided by Professor Ho-Joon Shin in Ajou University, which were used in the previous report [17]. To obtain mouse ascitic fluid, $1 \times 10^{7}$ cells were injected in incomplete Freund's adjuvant-primed ICR mice. Ascitic fluids harvested were further processed for purification of antibodies by protein A agarose 4B column (Incospharm, Korea) according to manufacturer's instruction.

Purified D2H $(1 \mathrm{mg} / \mathrm{ml})$ were gently mixed with conjugation buffer $\left(0.1 \mathrm{M} \mathrm{NaHCO}_{3}, \mathrm{pH} 8.5\right)$ for $30 \mathrm{~min}$ at room temperature (RT) with gentle rotation. After coumarinderived dendrimer (a kind donation of Dr Hak Sung Kim, Wonkwang University, Korea) was dissolved in DMSO $(1 \mathrm{mg} / \mathrm{ml})$, antibody (D7E) in conjugated buffer was incubated with 6 moles per mole of antibody for overnight at $4^{\circ} \mathrm{C}$. Then the mixture was filtered by using desalting column (Thermo Scientific ${ }^{\text {Tw }}$ Zeba $^{\text {Tm }}$ Spin Desalting columns) to remove free coumarin-derived dendrimer. Coumarin- 
derived dendrimer bioconjugate was collected with centrifugation at $1,000 \times \mathrm{g}$ for $2 \mathrm{~min}$ at $4^{\circ} \mathrm{C}$.

$\mathrm{D} 2 \mathrm{H}(1 \mathrm{mg} / \mathrm{ml})$ was conjugated with horseradish peroxidase (HRP) in EZ-Link ${ }^{\mathrm{mm}}$ Plus Activated Peroxidase (Thermo Scientific, Rockford, IL, USA) according to manufacturer's instructions. Briefly, $1 \mathrm{mg} / \mathrm{ml}$ of $\mathrm{D} 2 \mathrm{H}$ in carbonate-bicarbonate buffer ( $\mathrm{pH}$ 9.4) were reacted with $1 \mathrm{mg}$ of lyophilized peroxidase at RT for one hour. After additional reaction with $10 \mu \mathrm{L}$ of sodium cyanoborohydride for $15 \mathrm{~min}$ at $\mathrm{RT}$, reaction stopped by $20 \mu \mathrm{L}$ of quenching buffer for $15 \mathrm{~min}$ at RT. The HRP bioconjugates were further purified with conjugate purification kit (Thermo Scientific, Rockford, IL, USA) to remove unbound HRP.

\section{Fluorescence-linked immunosorbent assay (FLISA)}

FLISA were performed as previously described [13]. Plasmodium falciparum and Plasmodium vivax recombinant LDH (rLDH) were purchased from C\&K Bio Resource
Inc, Korea. Briefly, $1 \mu \mathrm{g} /$ well D7E were prepared for coating a black 96-well microtitre plate (Greiner, Germany) overnight and next day, plate was blocked with $2 \%$ caseinbased blocking buffer at $37^{\circ} \mathrm{C}$. After two hours, plate was washed with $200 \mu \mathrm{L}$ of phosphate buffered saline with $0.05 \%$ Tween 20 (PBS-T, pH 7.4) and $100 \mu \mathrm{L}$ of sample were added to each well and incubated at $37^{\circ} \mathrm{C}$. After two hours, plate was washed with $200 \mu \mathrm{L}$ of PBS-T. Finally, $200 \mu \mathrm{L}$ of coumarin-derived dendrimer-conjugated D2H was added to detect antigens for one hour. Stringent washing with PBS-T was performed six times to remove unbound antibodies and $100 \mu \mathrm{L}$ of PBS was added to each well to measure the fluorescence. Fluorescence with $460 \mathrm{~nm}$ excitation and $560 \mathrm{~nm}$ emission was measured using an Infinite F200 microplate reader (TECAN, Männedorf, Switzerland). Relative fluorescence was determined by extracting fluorescence value of negative control.

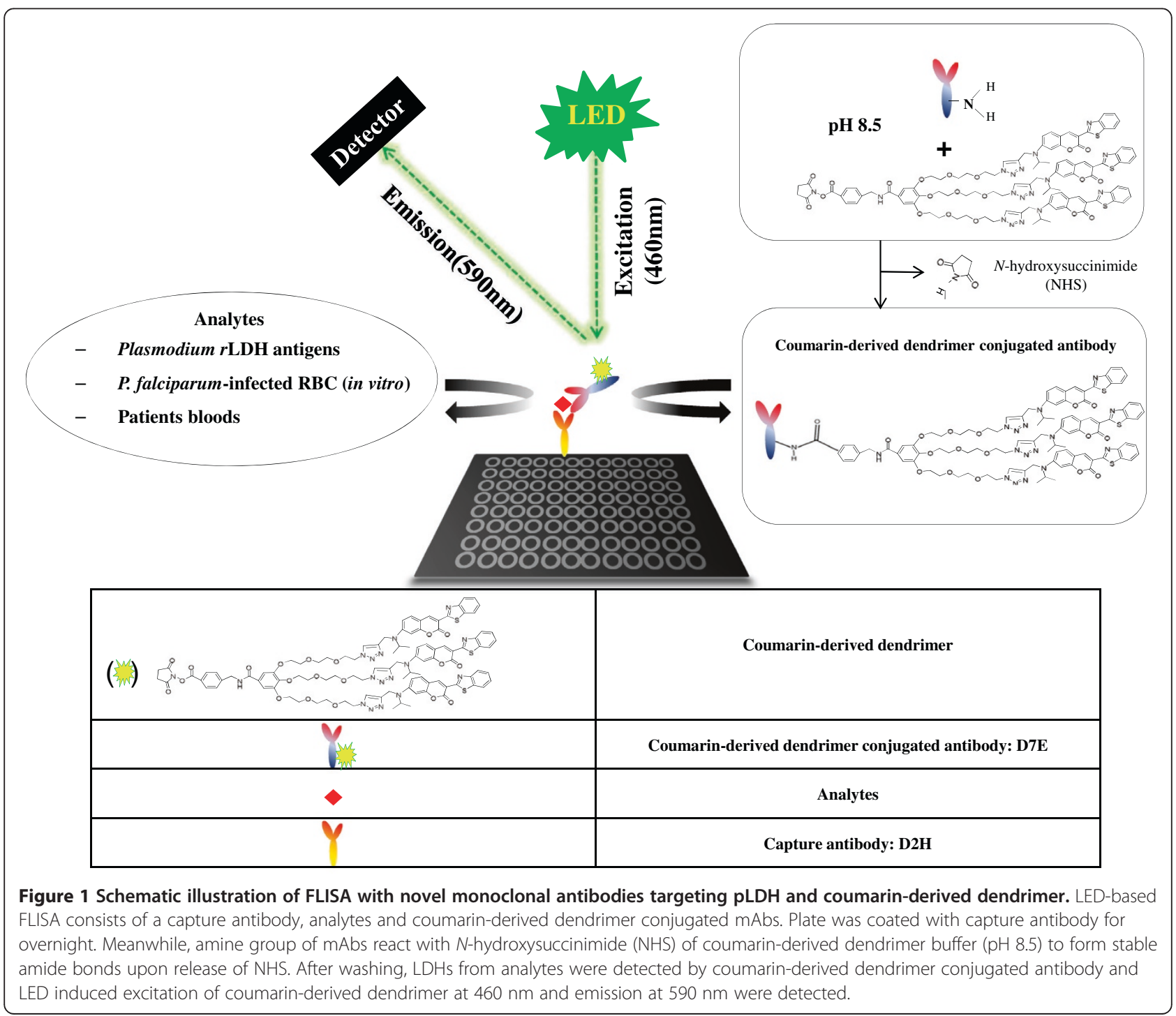




\section{Sandwich enzyme-linked immunosorbent assay (ELISA)}

Polystyrene, 96-well plate (NUNC, Pasadena, Texas, USA) was coated with $100 \mu \mathrm{L}(10 \mu \mathrm{g} / \mathrm{mL})$ of D7E in coating buffer (50 mM bicarbonate/carbonate coating buffer, $\mathrm{pH}$ 9.6) and stored in an incubator overnight at $4^{\circ} \mathrm{C}$. After incubation, the plate well was washed four times with $200 \mu \mathrm{L}$ of PBS-T and blocked with $1 \%$ casein-based blocking buffer at $37^{\circ} \mathrm{C}$ for two hours. After washing with PBS-T buffer twice, differently diluted analytes were allowed to each well. The $100 \mathrm{uL}$ of HRP conjugates D2H (2 ug/ml) was applied to each well at $27^{\circ} \mathrm{C}$ for one hour. After washing with PBS-T five times, plates were filled with $100 \mu \mathrm{L}$ of 3,3,5,5;-tetra methyl benzidine (TMB) substrate solution (Invitrogen, Camarillo, CA, USA) in the dark for $30 \mathrm{~min}$, following stopping with additional $100 \mu \mathrm{L}$ of sulphuric acid $(0.5 \mathrm{M})$ per well. Optical density $(\mathrm{OD})$ was measured by a microplate reader at $450 \mathrm{~nm}$. Data were expressed as mean \pm standard deviation.

\section{Ethical considerations}

Professor Tai-Soon Yong (Yonsei University, College of Medicine, Seoul, Korea) kindly provided amoeba-infected specimens and Professor Ho-Woo Nam (Catholic University, College of Medicine, Seoul, Korea) kindly provided Toxoplasma gondii-infected samples. Malaria patient samples were provided from professor Eun-Taek Han (Kangwon National University, School of Medicine, Chuncheon, Korea). The study was approved by the Kangwon National University Hospital Institutional Review Board (Approval No. 10-041-07).

\section{Results}

Coumarin-derived dendrimer was chosen as labelling fluorophore, which was confirmed to have good spectroscopic properties in previous study [13]. In this study, two newly developed mAbs targeting pLDH were used for FLISA instead of commercialized mAbs of $\mathrm{pLDH}$, and performance in FLISA was defined to determine antigen-antibody reactivity. Figure $1 \mathrm{~A}$ illustrates the schematic representations of the conjugation reactions to understand the principle of the coumarin-derived dendrimer-based FLISA with three analytes (Plasmodium recombinant $\mathrm{LDH}$, in vitro P. falciparum-infected human RBC, and patients bloods). $N$ hydroxysuccinimide (NHS) esters of coumarin-derived dendrimers react with primary amine groups $\left(-\mathrm{NH}_{2}\right)$ of mAbs in buffer ( $\mathrm{pH} 8.5)$ to form stable amide bonds upon release of NHS. Further FLISA procedure is followed on conventional sandwich ELISA and in FLISA, fluorescence intensity indicates the interaction between parasite antigen and coumarin-derived dendrimer-conjugated antibody. The wavelength of maximum absorption (usually the same as the excitation maximum) of coumarin-derived dendrimer is $460 \mathrm{~nm}$ and excitation spectrum of a given bioconjugate is $590 \mathrm{~nm}$ [13].

Plasmodium LDH is an enzyme of glycolytic pathway of different Plasmodium species at both the asexual and sexual stages and also correlated with the number of parasites present in the plasma of infected patients [19-21]. The LDH from P. vivax, P. malariae, and P. ovale has $87 \%$ sequence identity with $p \mathrm{LDH}$ from $P$. falciparum [22]. In current study, target epitope (1-31 amino acid) of Plasmodium LDH were aligned in BLAST, using BLASTP 2.2.29+ program and the epitope sequence of Plasmodium LDH shows $97-100 \%$ identities among seven Plasmodium species [P. falciparum (GenBank accession no. AEX28368.1), P. vivax (GenBank accession no. AAS77573.1), P. malariae (GenBank accession no. AAS77572.1), P. ovale (GenBank accession no. AAS77571.1), P. knowlesi (GenBank accession no. AEL88505.1), Plasmodium yoelii (GenBank accession no. XP724101.1), and Plasmodium berghei (GenBank accession no. XP679401.1)]. In contrast, the eptitope of Plasmodium LDHs shows $76 \%$ identities of Emeiria maxima LDH (GenBank accession no. AAN38977.1) and $66 \%$ of Toxoplasma gondii LDH (GenBank

Table 1 Alignment of pLDH epitope among Plasmodium species

\begin{tabular}{|c|c|c|c|}
\hline Species & Epitope region in LDH & Identity & GenBank accession no. \\
\hline P. vivax & 75 FTKAPGKSDKEWNRDDLLPLNNKIMIEIGGH 105 & $31 / 31(100 \%)$ & AAS77573.1 \\
\hline P. falciparum & 61 FTKAPGKSDKEWNRDDLLPLNNKIMIEIGGH 91 & $31 / 31(100 \%)$ & AEX28368.1 \\
\hline P. knowlesi & 82 FTKAPGKSDKEWNRDDLLPLNNKIMIEIGGH 112 & $31 / 31(100 \%)$ & AEL88505.1 \\
\hline P. yoelii $17 X N L$ & 82 FTKAPGKSDKEWNRDDLLPLNNKIMIEIGGH 112 & $31 / 31(100 \%)$ & XP724101.1 \\
\hline P. berghei ANKA & 82 FTKAPGKSDKEWNRDDLLPLNNKIMIEIGGH 112 & $31 / 31(100 \%)$ & XP679401.1 \\
\hline P. malariae & 75 FTKVPGKSDKKEWNRDDLLPLNNKIMIEIGGH 105 & $30 / 31(97 \%)$ & AAS77572.1 \\
\hline P. ovale & 75 FTKAPGKSDKEWNRDDLLPLNNKIMIEIGGH 105 & $31 / 31(100 \%)$ & AAS77571.1 \\
\hline Eimeria maxima & 88 TKIPGKSDKEWSRMDLLPVNIKIMREVGG 116 & $22 / 29(76 \%)$ & AAN38977.1 \\
\hline Toxoplasma gondii & 86 LTKVPGKSDKEWSRNDLLPFNAKIIREVA 114 & 19/29(66\%) & XP002368488.1 \\
\hline Homo sapiens & 98 AGARQQEGESRLNLVQRN123 & $7 / 31(23 \%)$ & CAE11711 \\
\hline
\end{tabular}

Plasmodium LDH epitope (FTKAPGKSDKEWNRDDLLPLNNKIMIEIGGH) is highly conserved among seven Plasmodium spp. and the percentage of sequence identity is determined by epitope alignments across the listed in NCBI. 
accession no. XP002368488.1). This epitope has only 26\% identities in Homo sapiens LDH (GenBank accession no. CAE11711) (Table 1). Therefore, antibodies targeting this epitope may act as pan-specific anti-LDH, which is able to react with most Plasmodium spp.

To investigate the ability of FLISA to quantify malaria antigen, FLISA were performed with different concentration of $P$. falciparum- and $P$. vivax-recombinant LDH antigens at six-point standard curve based on two-fold dilutions from 0.01 to $1,000 \mathrm{ng} / \mathrm{mL}$. Well-defined linear regressions were produced at FLISA for both $P$. falciparum- $\left(\mathrm{R}^{2}=0.972\right)$ and P. $\operatorname{vivax}\left(\mathrm{R}^{2}=0.967\right) \mathrm{LDH}$ (Figure $2 \mathrm{~A}$ and $\left.\mathrm{B}\right)$. Plasmodium $\mathrm{LDH}$ antigen was detectable up to $10 \mathrm{ng} / \mathrm{mL}$ in ELISA at the same condition with FLISA (Figure 2C). As OD value of
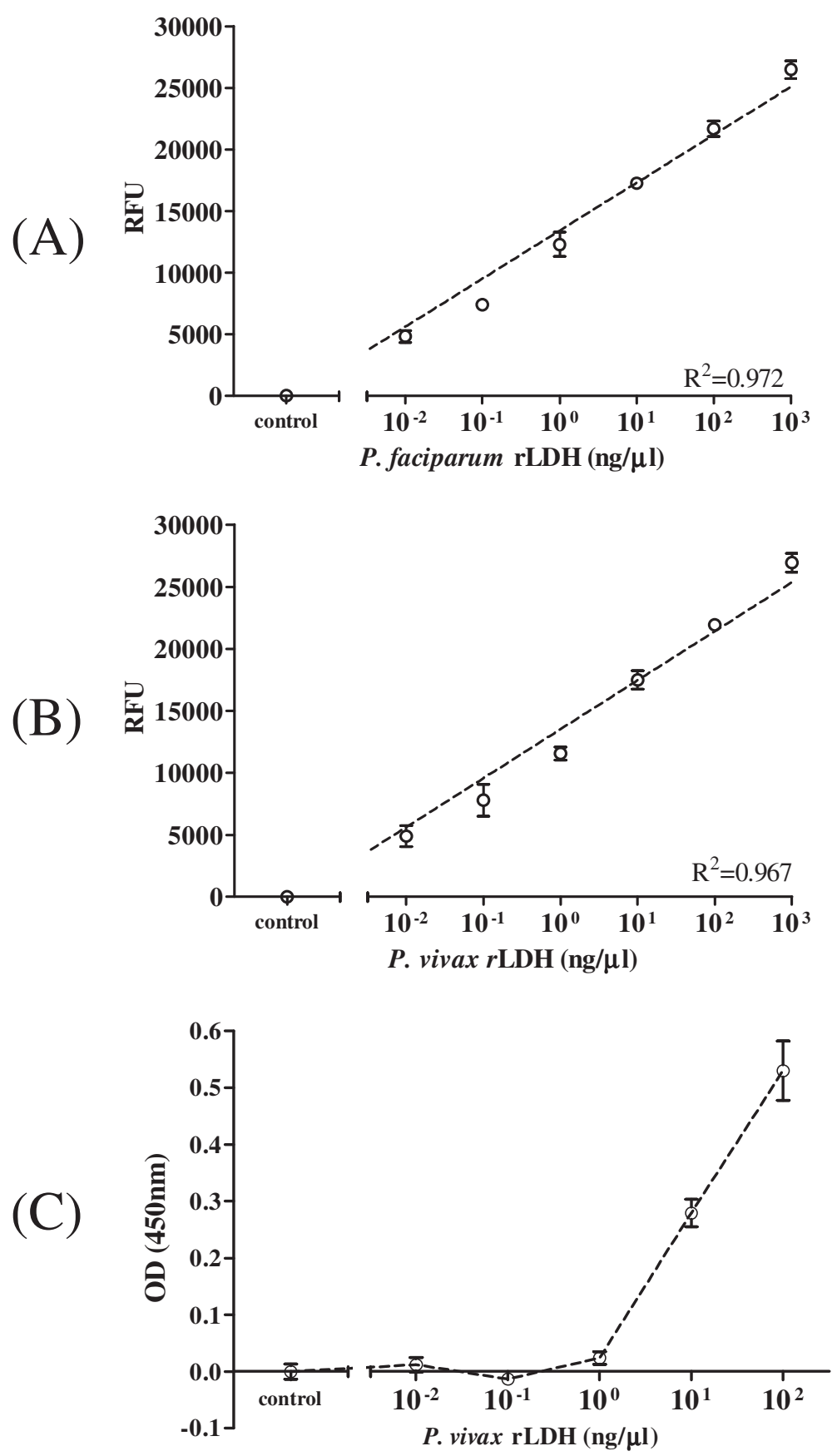

Figure 2 Comparison of FLISA and ELISA detectability against Plasmodium LDH. Standard curve for a detectable range of FLISA were generated: P. falciparum rLDH in FLISA (A), P. vivax rLDH in FLISA (B), and P. vivax rLDH in ELISA (C). In FLISA, 0.01 ng/uL of antigen was detectable but $10 \mathrm{ng} / \mathrm{uL}$ of antigen was a minimum detectable antigen level in ELISA. 


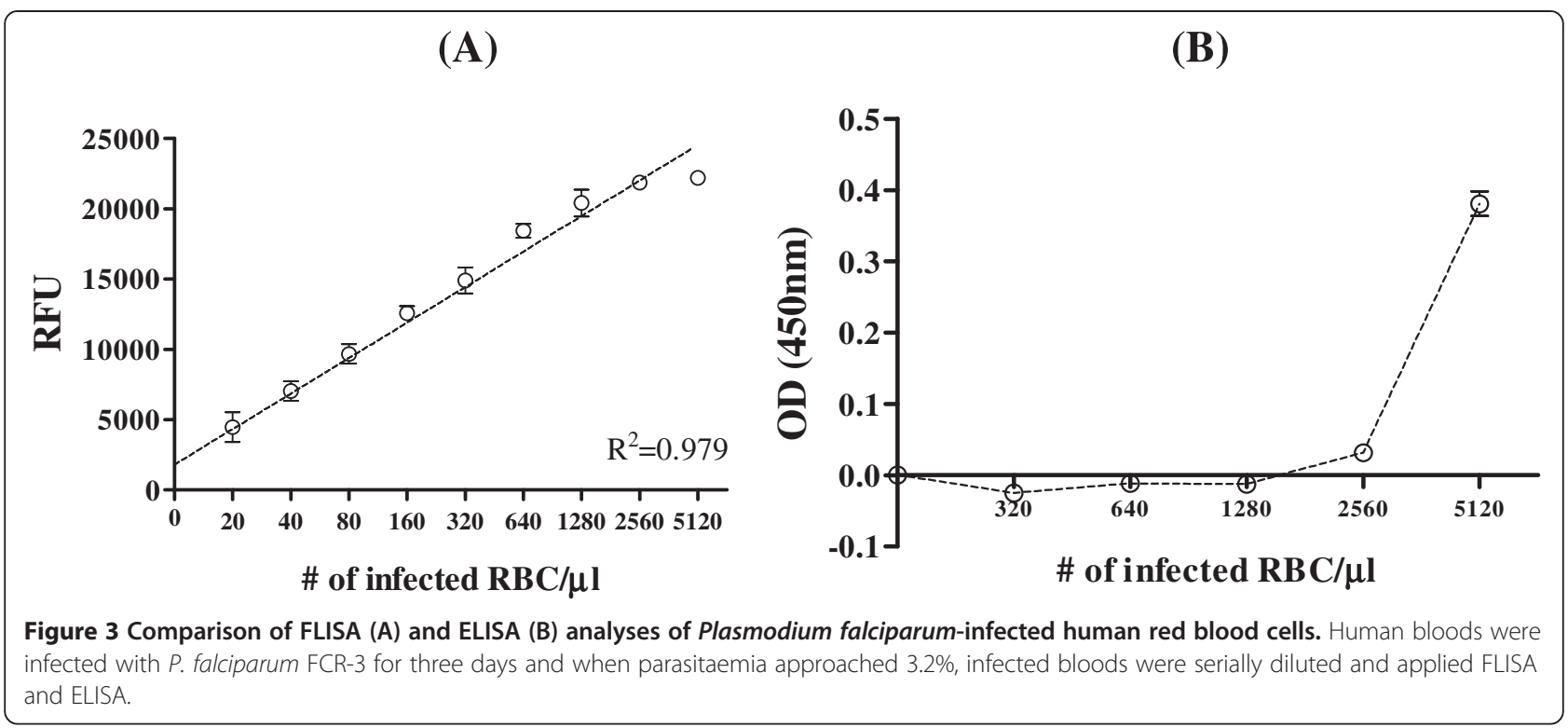

0.1 is positive, the detection threshold of FLISA is at least 1,000-fold higher than ELISA, implying that FLISA would contribute to increase detectability of pLDH in early infection when it is hard to be detected in conventional ELISA. Furthermore, in vitro-cultured P. falciparum was prepared to determine FLISA performance to detect $P$. falciparum-infected blood RBC. P. falciparum infected human RBC and cultured for three days to induce $3.2 \%$ of parasitaemia in $1.6 \times 10^{8}$ total RBC. As a result of FLISA, fluorescent intensity and $P$. falciparum density was highly correlated and reliable $\left(R^{2}=0.97\right)$, between 20 and 5,120 parasites (Figure 3A). In contrast, detection threshold of ELISA was 5,120 parasites (Figure 3B). Therefore, FLISA would be a useful diagnostic assay with high detectability to quantify low number of parasite density than ELISA.

To determine the sensitivity and specificity of FLISA, $P$. falciparum $(\mathrm{n}=9)$ and $P$. vivax $(\mathrm{n}=9)$ infected patient's bloods were applied to FLISA and FLISA showed 100\% of sensitivity (18/18). In contrast, non-malaria disease samples among healthy donors $(n=9), T$. gondii- $(n=9)$, and amoeba-infected patients $(n=9)$ showed one false positive reactivity with $T$. gondii-infected patient blood. Therefore, specificity of FLISA was 96.3\% (26/27) (Figure 4).

\section{Conclusion}

Since elimination of malaria infection by WHO, malaria prevalence is getting low but still prevalent worldwide. In Republic of Korea (ROK), after reemergence of malaria near location of demilitarized zone (DMZ) in 1993, the annual incidence has increased rapidly [23-25]. Until 2010 , ten cases of transfusion-transmitted malaria have been reported in ROK [26]. The incidence of transfusiontransmitted malaria among people residing in endemic areas is unknown and a substantial proportion of the population in malaria-endemic countries has asymptomatic parasitaemia [16]. Therefore, development of enhanced Plasmodium blood screening test is advocated to prevent spread by transfusion in blood banks and in ROK, ELISA has been developed to screen and monitor transfusion-transmitted malaria $[27,28]$. There are two main aspects to keep in mind when considering malaria risk and transfusion, such as the malaria risk associated with any individual donor and the ability of the systems to identify and manage the donor [29]. The development of tests that are able to screen and identify donors potentially infectious for parasitic infections without causing the deferral

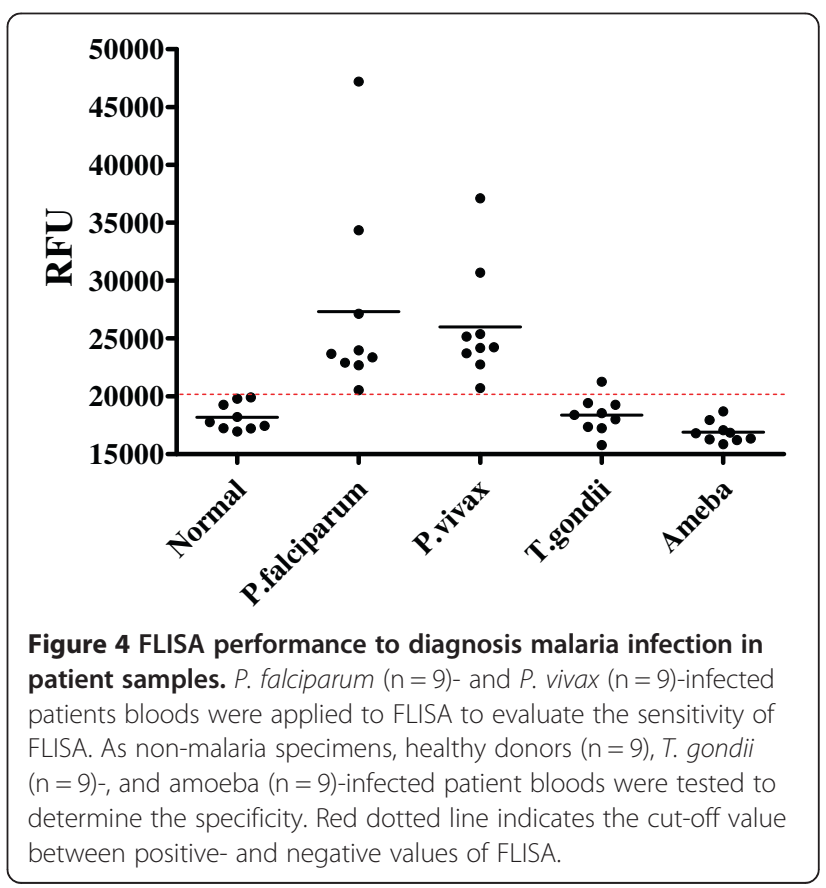


of a large number of non-infectious donors is considered as one goal for prevention [30]. For this reason, coumarinderived dendrimer-based FLISA assay was developed and compared to conventional ELISA. Because fluorescent density was highly correlated with parasite numbers, FLISA is applicable for quantification of parasite numbers in addition to diagnosis of Plasmodium infection. Therefore, FLISA has a potential as malarial diagnostic to facilitate the accurate diagnosis of Plasmodium infection and it would be an apparent alternative assay to determine Plasmodium parasite density. Because fluorescent intensity is correlated with malaria density with high sensitivity, FLISA may be considered as a feasible solution for highthroughput analysis of malaria infection during blood transfusion in ROK. Further studies should assess the diagnostic performance for other Plasmodium spp. infection and asymptomic parasitaemia patients.

\section{Competing interests}

The authors have declared that they have no competing interests.

\section{Authors' contributions}

SJ, DT, JH, JY, WJ, and HJ carried out the assays and analysed the results; SJ, ET and HP wrote the manuscript; SJ, WJ, HJ, ET, and HP conceived and designed the experiments. All authors read and approved the final manuscript.

\section{Acknowledgements}

This research was supported by a Research fund (2013E5400800) of the Korea Centers for Disease Control and Prevention and by the Public Welfare \& Safety Research Program through the National Research foundation of Korea (NRF) funded by the Ministry of Science, ICT \& Future Planning (2010-0020803)

\section{Author details}

'Zoonosis Research Center, Department of Infection Biology, School of Medicine, Wonkwang University, Iksan, Jeonbuk 570-749, Republic of Korea. ${ }^{2}$ Department of Medical Environmental Biology and Tropical Medicine, School of Medicine, Kangwon National University, Chuncheon, Gangwon-do, Republic of Korea. ${ }^{3}$ Division of Malaria and Parasitic Disease, Korea National Institute of Health, Osong 363-951, Republic of Korea. ${ }^{4}$ Department of Microbiology, Ajou University School of medicine, Suwon 443-721, Republic of Korea.

\section{Received: 20 May 2014 Accepted: 4 July 2014}

Published: 10 July 2014

\section{References}

1. WHO: World Malaria Report. [http://www.who.int/campaigns/malaria-day/ 2013/en/index.html]

2. Dhingra N, Jha P, Sharma VP, Cohen AA, Jotkar RM: Adult and child malaria mortality in ndia: a nationally representative mortality survey. Lancet 2010, 376:1768-1774.

3. Jha P: Reliable mortality data: a powerful tool for public health. Natl Med J India 2001, 14(suppl 3):129-131.

4. Jha P, Gajalakshmi V, Gupta PC: Prospective study of one million deaths in India: rationale, design, and validation results. PLoS Med 2006 3(suppl 2):e18.

5. Johnston SP, Pieniazek NJ, Xayavong MV, Slemenda SB, Wilkins PP, da Silva $\mathrm{AJ}: \mathrm{PCR}$ as a confirmatory technique for laboratory diagnosis of malaria. J Clin Microbiol 2006, 44:1087-1089.

6. Bejon P, Andrews L, Hunt-Cooke A, Sanderson F, Gilbert SC, Hill AV: Thick blood film examination for Plasmodium falciparum malaria has reduced sensitivity and underestimates parasite density. Malar J 2006, 8:104.

7. Haanshuus CG, Mohn SC, Mørch K, Langeland N, Blomberg B, Hanevik K: A novel, single-amplification PCR targeting mitochondrial genome highly sensitive and specific in diagnosing malaria among returned travellers in Bergen, Norway. Malar J 2013, 12:26.

8. Milne LM, Kyi MS, Chiodini PL, Warhurst DC: Accuracy of routine laboratory diagnosis of malaria in the United Kingdom. J Clin Pathol 1994, 47:740-742.

9. Mangold KA, Manson RU, Koay ES, Stephens L, Regner M, Thomson RB Jr, Peterson LR, Kaul KL: Real-time PCR for detection and identification of Plasmodium spp. J Clin Microbiol 2005, 43:2435-2440.

10. Kamau E, Tolbert LS, Kortepeter L, Pratt M, Nyakoe N, Muringo L, Ogutu B, Waitumbi JN, Ockenhouse CF: Development of a highly sensitive genus-specific quantitative reverse transcriptase real-time PCR assay for detection and quantitation of plasmodium by amplifying RNA and DNA of the 18S rRNA genes. J Clin Microbiol 2011, 49:2946-2953.

11. Snounou G, Viriyakosol S, Jarra W, Thaithong S, Brown KN: Identification of the four human malaria parasite species in field samples by the polymerase chain reaction and detection of a high prevalence of mixed infections. Mol Biochem Parasitol 1993, 58:283-292.

12. Noedl H, Yingyuen K, Laoboonchai A, Fukuda M, Sirichaisinthop J, Miller RS Sensitivity and specificity of an antigen detection ELISA for malaria diagnosis. Am J Trop Med Hyg 2006, 75:1205-1208.

13. Song HO, Lee B, Bhusal RP, Park B, Yu K, Chong CK, Cho P, Kim SY, Kim HS, Park H: Development of a novel fluorophore for real-time biomonitoring system. PLoS One 2012, 7:e48459.

14. Mendoza NM, Cucunubá ZM, Aponte S, González NE, Bernal SD: Field evaluation for diagnostic accuracy of the rapid test SD Bioline Malaria Antigen Pf/Pv in Colombia. Biomedica 2013, 33:587-597.

15. Coleman RE, Maneechai N, Rachaphaew N, Kumpitak C, Miller RS, Soyseng V, Thimasarn K, Sattabongkot J: Comparison of field and expert laboratory microscopy for active surveillance for asymptomatic Plasmodium falciparum and Plasmodium vivax in western Thailand. Am I Trop Med Hyg 2002, 67:141-144.

16. Nansseu JR, Noubiap JJ, Ndoula ST, Zeh AF, Monamele CG: What is the best strategy for the prevention of transfusion-transmitted malaria in sub-Saharan African countries where malaria is endemic? Malar J 2013, 12:465.

17. Kim JH, Lee J, Sohn HJ, Song HO, Kim JY, Lee WJ, Park H, Shin HJ: Production of monoclonal antibodies for Plasmodium vivax lactate dehydrogenase and patient sera screening using sandwich ELISA. Parasitol Res 2012, 111:1645-1650.

18. Miao J, Cui L: Rapid isolation of single malaria parasite-infected red blood cells by cell sorting. Nat Protoc 2011, 6:140-146.

19. Sousa LP, Mariuba LA, Holanda RJ, Pimentel JP, Almeida ME, Chaves YO, Borges D, Lima E, Crainey JL, Orlandi PP, Lacerda MV, Nogueira PA: A novel polyclonal antibody-based sandwich ELISA for detection of Plasmodium vivax developed from two lactate dehydrogenase protein segments. BMC Infect Dis 2014, 14:49.

20. Doderer C, Heschung A, Guntz P, Cazenave JP, Hansmann Y, Senegas A, Pfaff AW, Abdelrahman T, Candolfi E: A new ELISA kit which uses a combination of Plasmodium falciparum extract and recombinant Plasmodium vivax antigens as an alternative to IFAT for detection of malaria antibodies. Malar J 2007, 6:19.

21. Martin SK, Rajasekariah GH, Awinda G, Waitumbi J, Kifude C: Unified parasite lactate dehydrogenase and histidine-rich protein ELISA for quantification of Plasmodium falciparum. Am J Trop Med Hyg 2009, 80:516-522.

22. Brown WM, Yowell CA, Hoard A, Vander Jagt TA, Hunsaker LA, Deck LM: Comparative structural analysis and kinetic properties of lactate dehydrogenases from the four species of human malarial parasites. Biochemistry 2004, 43:6219-6229.

23. Korea Centers for Disease Control \& Prevention. http://cdc.go.kr/CDC/ together/CdcKrTogether0302.jsp?menulds=HOME001-MNU1154-MNU0004MNU0088\&fid $=51 \& q \_$type $=\& q \_v a l u e=\& c i d=9885 \&$ pageNum $=1$.

24. Global Health Group Project team: Eliminating malaria in the Democratic People's Republic of Korea. San Francisco: UCSF; 2012.

25. Park JW, Jun G, Yeom JS: Plasmodium vivax malaria: status in the Republic of Korea following reemergence. Korean J Parasitol 2009, 47(Suppl):S39-50.

26. Cho YH, Kwon SY, Seo DH, Kim SI: Transfusion transmitted malaria in Korea. Korean J Blood Transfus 2001, 12:263-270.

27. Nam MH, Kim JS, Cho CH, Han ET, Lee WJ, Lee HK, An SS, Lim CS, Lee KN: Evaluation of Plasmodium vivax ELISA for the blood screen. Trop Med Int Health 2010, 15:1436-1441. 
28. Oh JS, Kim JS, Lee CH, Nam DH, Kim SH, Park DW, Lee CK, Lim CS, Park GH: Evaluation of a malaria antibody enzyme immunoassay for use in blood screening. Mem Inst Oswaldo Cruz 2008, 103:75-78.

29. Kitchen AD, Chiodini PL: Malaria and blood transfusion. Vox Sang 2006 90:77-84.

30. Singh G, Sehgal R: Transfusion-transmitted parasitic infections. Asian J Transfus Sci 2010, 4:73-77.

doi:10.1186/1475-2875-13-266

Cite this article as: Yeo et al:: Performance of coumarin-derived dendrimerbased fluorescence-linked immunosorbent assay (FLISA) to detect malaria antigen. Malaria Journal 2014 13:266.

\section{Submit your next manuscript to BioMed Central and take full advantage of:}

- Convenient online submission

- Thorough peer review

- No space constraints or color figure charges

- Immediate publication on acceptance

- Inclusion in PubMed, CAS, Scopus and Google Scholar

- Research which is freely available for redistribution 